\title{
RC-MAPS: Bridging the Comprehension Gap in EAP Reading
}

\section{Angela Meyer Sterzik and Carol Fraser}

In academic environments, reading is assigned not simply to transmit information; students are required to take the information, and based on the task set by the instructor, assess, analyze, and critique it on the basis of personal experiences, prior knowledge, and other readings (Grabe, 2009). Thus text-based comprehension (Kintsch, 1998) alone is not sufficient for academic success. Top-down processing is also required; this involves applying prior knowledge to define purpose(s), to make and verify hypotheses, and to infer and question content (Macaro \& Erler, 2008; Urquhart \& Weir, 1991). Although research has given teachers direction regarding the approach to use when providing strategy instruction in their classrooms, it has been left to teachers to develop the specific teaching tools required. In this article, I propose Reading Comprehension MAP for Situation-based comprehension (RC-MAPS): an instructional technique that provides teachers with an easily modified tool to assist in developing interpretative comprehension skills among second-language readers in academic environments through the strategy of questioning.

Dans les milieux académiques, on ne demande pas aux élèves de lire tout simplement pour transmettre de l'information; selon la tâche exigée par l'enseignant, on s'attend également à ce qu'ils évaluent, analysent et critiquent l'information à partir de leurs expériences personnelles, de leurs connaissances antérieures et de lectures supplémentaires (Grabe, 2009). La compréhension de textes (Kintsch, 1998) ne suffit donc pas pour assurer la réussite académique. Le traitement descendant est également nécessaire; cette stratégie consiste en l'application de connaissances antérieures à la définition d'objectifs, la création et la vérification d'hypothèses, la dérivation d'une conclusion et le questionnement du contenu (Macaro \& Erler, 2008; Urquhart $\mathcal{E}$ Weir, 1991). Alors que la recherche propose aux enseignants des orientations quant aux stratégies à proposer en classe, les enseignants doivent développer eux-mêmes les outils pédagogiques requis. Dans cet article, je propose «Reading Comprehension MAP for Situation-based comprehension», une technique pédagogique qui offre aux enseignants un outil facilement modifiable qui appuie, par la stratégie du questionnement, le développement des habiletés de compréhension interprétative chez les lecteurs en langue seconde dans des milieux académiques.

\section{Introduction}

Reading is an essential academic skill, but what is reading and how does one do it? I have asked my TESL class these questions, and although they gener- 
ally agreed on a definition of what reading is, the how appeared to be much more difficult to answer. The general consensus when asked "What do you do when you read?" was "I don't know; I just read." In order to teach students how to read, teachers need to be able to articulate not only what is required, but more importantly, how to do it.

In academic environments, reading is the basis for much of the knowledge that both first-language (L1) and second-language (L2) students require to succeed. Students are expected to read not only multiple texts and comprehend them in the sense of determining the writer's intended meaning, but also to interpret, that is, analyze, synthesize, and evaluate the texts, in order to develop their knowledge base (Grabe, 2009; Grabe \& Stoller, 2002). These tasks require interaction with texts and the integration of information in and between texts (Grabe; Grabe \& Stoller; Kintsch, 1998). Before interaction and integration can occur, however, readers must understand the author's meaning or achieve what Kintsch in his Construction-Integration Model of Discourse Processing has labeled a text-based representation of meaning. The focus/goal of this text-based representation is to identify and organize main ideas and key support in a hierarchical structure. Kintsch (1986) associates this with remembering a text. Armed with a solid text-based level of comprehension, readers are then prepared to interact with and integrate the newly acquired knowledge into their own knowledge base to achieve a more interpretative, situation-based representation of meaning (Kintsch, 1998). At the level of situation-based comprehension, readers transform information in the text in terms of their own purpose and knowledge base (Kintsch, 1986).This level of comprehension is associated with learning from a text (Kintsch, 1986, 1998); unfortunately, these interpretative comprehension skills are challenging reading skills for many university students.

Most students in English for Academic Purposes (EAP) reading classes at the college and university levels are fluent readers in their L1s. They are able to interact with texts and integrate the information when it is in their mother tongue, so one would expect them to be able to transfer these skills to their L2. In our experience, however, this is often not the case. Through the explicit instruction and practice of strategies such as context clue use, rhetorical pattern recognition, and macro- and micro-idea identification, students are usually able to tackle challenging texts successfully and independently and achieve solid text-based comprehension. Yet many still have difficulty bridging the gap from a more literal text-based comprehension to a more interpretive, situation-based comprehension even when what is expected is made explicit.

Through her academic journey and research, the first author realized that the problem did not lie in the students' understanding of what was being asked of them, but rather in how to do it. The students knew where they needed to 
go; they simply did not have a map to get there. With this realization, she embarked on a quest for a possible solution, out of which emerged Reading Comprehension MAP for Situation-based comprehension (RC-MAPS). RC-MAPS is a pedagogical tool intended to be used in EAP classrooms to facilitate and foster interpretative reading comprehension skills in L2 learners. RC-MAPS is a strategy training procedure to help students to cope with reading challenging texts and to develop strategies for future academic work. It consists of simple, task-specific questioning guidelines, along with graphic organizers to assist L2 readers in bridging the gap between text-based and situation-based reading comprehension in academic tasks. RC-MAPS is intended to be used as a modeling tool during explicit questioning instruction and as scaffolding to assist L2 readers in moving from awareness, to practice, to routine use of task-specific, metacognitive questioning strategies.

An important factor in text-based comprehension is an awareness of how texts are structured and organized (Grabe, 2004; Jiang \& Grabe, 2007). Graphic organizers (see Appendix A) are visual representations of the organization and interrelationships of the macro- and micro-hierarchical structures of texts. The use of graphic organizers in both L1 and L2 research has demonstrated their positive effects in learners' construction of a text-based level of comprehension (Jiang \& Grabe). As such, they are commonly used in reading classrooms to facilitate the instruction of identifying discourse patterns as a reading strategy (Jiang \& Grabe). To date, graphic organizers have been used successfully to foster text-based comprehension (Jiang \& Grabe), but they have not been applied to situation-based comprehension. Moreover, although situation-based comprehension is required for academic tasks (Grabe, 2009; Grabe \& Stoller, 2002), we are unaware of a pedagogical tool with a specific strategic focus on fostering situation-based comprehension; however, RC-MAPS fills this gap.

In the context of RC-MAPS, graphic organizers are first used as a visual representation of the organizational structure of texts. Furthermore, as Jiang and Grabe (2007) suggest, the graphic organizers used in RC-MAPS are specific to rhetorical patterns (see Appendix A). RC-MAPS provides a map to guide students from text-based to situation-based comprehension by using graphic organizers in two stages:

1. To scaffold and demonstrate text-based comprehension by paraphrasing and organizing the author's ideas into their intended hierarchy (thesis, main ideas, supporting details).

2. To scaffold and develop situation-based comprehension through critical questioning and responding to questions.

By integrating the strategy of critical questioning, RC-MAPS extends the use of graphic organizers from promoting text-based comprehension to also fostering situation-based comprehension in $\mathrm{L} 2$ readers. 


\section{Theoretical Frameworks}

\section{Construction-Integration Model}

Reading comprehension is often seen as consisting of two main processing categories: decoding and comprehending (Grabe \& Stoller, 2002; Macaro \& Erler, 2008). Decoding refers to the identification and processing of basic linguistic units (letter patterns, words, syntactic patterns, and semantic propositions), whereas comprehending involves the integration of information from these knowledge sources to construct a mental representation of the entire text (Fraser, 2004; Grabe, 2009; Grabe \& Stoller, 2002; Kintsch, 1998; Macaro \& Erler, 2008). In comprehending, fluent readers remember the prior propositions and mentally attach them to the new propositions to create a mental representation of the author's meaning (Kintsch; Koda, 2005; Macaro \& Erler; Urquhart \& Weir, 1998). Kintsch refers to this type of understanding as constructing a text-based representation of meaning. Text-based comprehension is associated with comprehending the words and sentences; it underlies the ability to recall and summarize information given by the author. Text-based comprehension is typically required in academic settings, but more importantly, it is also required for students to move from summarytype tasks to more difficult interpretative academic tasks such as analyzing, assessing, and synthesizing information (Grabe; Kintsch).

In academic environments, reading is assigned not simply to transmit information; students are required to take the information and based on the task set by the instructor, assess, analyze, and critique it in relation to personal experiences, prior knowledge, and/or other readings (Grabe, 2009). Thus text-based comprehension alone is not sufficient for academic success. Top-down processing is also required, and this involves applying prior knowledge to define purpose(s), make and verify hypotheses, infer to fill gaps, and question content (Macaro \& Erler, 2008; Urquhart \& Weir, 1991). Readers must be able to integrate and apply prior knowledge to their developing text-based understanding in order to interpret a text appropriataely (Grabe; Kintsch, 1998; Koda, 2005). Kintsch describes the integration of the text-based understanding and the reader's background knowledge as creating a situation-based representation of meaning. This integration is associated with learning, and the recall of information is reconstructive and conceptually driven. This interpretive process underlies the ability to analyze, synthesize, and evaluate information, all typical tasks in academic settings (Grabe; Kintsch). Furthermore, as Grabe notes, this integration is often achieved through critical questioning.

It is important to note that the quality of the situation-based representation depends not only on the reader's knowledge base, but also on the quality (i.e., accuracy and completeness) of the text-based comprehension (Koda, 2005). Moreover, Grabe (2009) states that to achieve an effective integration 
of text-based with situation-based representations, skilled readers use strategies to engage their personal needs and goals when reading a text. For example, while reading a difficult text, skilled readers employ multiple strategies, often concurrently, such as reflecting on the content, making inferences to close gaps, and interpreting the text (Grabe). Unfortunately, because of the language issues that L2 readers face, even those who are fluent, strategic readers in their L1 do not necessarily transfer L1 strategies to the L2 reading context (Clarke, 1980; Heeney, 2005; Macaro \& Erler, 2008; Shih, 1992). ESL students often complain that applying what they read to academic tasks is one of their most difficult tasks (Fraser, 1989). Thus teaching students strategies to bridge the gap between constructing a text-based understanding of text and developing an interpretative situation-based understanding is a worthy instructional goal in the EAP reading class.

\section{Direct Strategy Instruction}

Strategies are deliberate, controlled, selected actions that readers employ to achieve comprehension goals effectively and efficiently (Allen, 2003; Carrell, Gajdusek, \& Wise, 1998; Heeney, 2005; Macaro \& Erler, 2008; Zhang, 2007). Cognitive reading strategies include actions such as paraphrasing, summarizing, elaborating, inferencing, and questioning to enhance comprehension (Allen; Grabe, 2009; Heeney; Shih, 1992; Yang, 2006). Implicated in this strategy use is metacognitive knowledge or readers' awareness of the strategic choices available and their deliberate use of one or more strategies to attend to comprehension breakdowns as well as to check, monitor, evaluate, revise, and select cognitive strategies (Salataci \& Akyel, 2002).

The two aspects of metacognition are knowledge and regulation (Carrell et al., 1998). Knowledge incorporates knowing which strategies are available, how to perform them, and why to choose a specific strategy. Regulation is the control of the strategies and includes planning, monitoring, testing, revising, and evaluating the effectiveness of strategies (Carrell et al.). Skilled readers employ cognitive strategies automatically, but they also engage in metacognition they perceive reading as challenging (Clarke, 1980; Grabe, 2009; Koda, 2005). L2 students in academic settings are often given readings that they find difficult. Reading instructors can develop learners' metacognitive awareness, along with their repertoire of cognitive strategies, to help students succeed in academic environments (Clarke). Research (Fraser, 1989; Grabe, 2009; Koda) indicates that the most effective approach to strategy training is direct teaching, "the explicit explanation, demonstration, and practice of selected strategies" (Fraser, p. 76).

\section{RC-MAPS: Metacognitive Strategy Training Technique}

RC-MAPS makes use of dual-purpose graphic organizers to guide students first to demonstrate text-based comprehension and then to develop and ex- 
pand situation-based comprehension. Once students have been introduced to and have practiced filling in scaffolded (i.e., partly completed by the teacher) graphic organizers that represent the specific discourse structures of the texts (see Appendix A), they are instructed to create the appropriate style of graphic organizer for a text (see Jiang \& Grabe, 2007, for more detail). Students who create a graphic organizer themselves have been shown to perform better on content-recall tasks than those who are given one generated by a teacher.

\section{A Text-Based Comprehension Lesson with RC-MAPS}

Overall, text-based comprehension requires students to remember propositions (i.e., ideas) and to attach them to new propositions as they read (Grabe, 2009; Grabe \& Stoller, 2002; Kintsch, 1998). If students focus on decoding, they tend to take longer to read, and hence they forget prior propositions (Grabe). RC-MAPS allows students to read and write at their own pace to create a written record to which to refer. Using RC-MAPS, students graphically organize the macro- and micro-propositions (main ideas, supporting details, etc.) put forth by the author, both during and after reading the text. They are encouraged to paraphrase the original text and to summarize it in point form in their graphic organizers. Having such a written record helps them to integrate and recall information and ideas.

The following lesson has been used with advanced EAP reading classes. It can easily be modified for lower levels by choosing a level-appropriate text (e.g., instead of a 5-paragraph expository text, beginners could use an 8-10sentence paragraph). When introducing RC-MAPS for the first time, the reading should be at or slightly below students' proficiency level, as

limited language proficiency appears to exert a powerful effect on the behaviours utilized by readers ... [and] ... limited control over the language "short circuits" the good reader's system, causing $\mathrm{him} /$ her to revert to poor reader strategies when confronted with a difficult ... task in the second language. (Clarke, 1980, p. 206)

In addition, the text should be on a topic previously studied to ensure appropriate background knowledge. Last, students should have been taught and should have practiced how to identify and highlight the main ideas and supporting details, as well as how to make paraphrased, point-form marginal notes.

As the topic of this reading is homeopathy (see Appendix B), students' background knowledge can be activated with a class discussion on current medical issues and trends. For example, the instructor might ask, "What do you know about H1N1? SARS? The common cold? How do doctors treat these illnesses? How do people treat themselves? What are the treatment options you are aware of, both here and in your home countries?" After the preread- 
ing discussion, the instructor should distribute the reading and ask students to preview the text for the main topic and purpose of the text; this should be followed by a short discussion. This initial reading activity can also be given as homework in the preceding class.

The students' next task is to read the text more carefully and to underline or highlight the main ideas and supporting details in each paragraph. This could also have been done as a homework assignment. In order to monitor and assess the students' text-based comprehension of the text before they use their RC-MAPS, instructors may ask students to work in pairs or small groups to compare and discuss the macro- and micro-propositions that each student identified in the text while creating paraphrased marginal notes for each paragraph. This follow-up activity follows Vygotsky's (1978) Zone of Proximal Development (ZPD) theory in which non-experts can learn from interactions with other non-experts. As well, the teacher can circulate, helping groups to reach consensus on comprehension problems; this extension activity also places students in the ZPD because of the interaction with an expert (Vygotsky). Finally, students' comprehension and highlighting can be assessed by the teacher with each pair/group or as a class, using the visual of a "correctly" highlighted text for comparison and discussion. The collaborative discussion of the highlighting also serves as a means to teach the students to monitor their own understanding of the hierarchical structure of information in the text.

Next, students are instructed to use their marginal notes and highlighting to create a text-based RC-MAPS. Depending on how familiar students are with graphic organizers, scaffolded versions may be used in which students need to fill in only some of the missing information, as other details are already present, thereby allowing more checks of their hierarchal structure of text propositions. For example, some information has been provided in the Chart Style graphic organizer (see Appendix A) for the Homeopathy text. Finally, to demonstrate clearly text-based comprehension and to provide academic task practice, students should write a summary of the article based on their RC-MAPS. These summaries may be peer-edited, collaboratively written, and/or submitted for assessment and feedback.

\section{RC-MAPS: Situational Comprehension Through Questioning}

When students have constructed a text-based representation, the EAP reading classroom can begin to focus on situation-based comprehension. Once general information about questioning has been presented, students are introduced to the specific RC-MAPS Questioning Strategy.

First, they are introduced to the concept of questioning texts and how the reader's purpose and the academic task can affect the types of questions readers want or need to ask (Day \& Park, 2005; Grabe, 2009). Readers with varied purposes typically focus on and interpret text information variably: the ques- 
tions each asks and the answers to them will differ (Grabe). To illustrate, one can imagine how differently a house-hunter and a thief will read and interpret an MLA house-for-sale listing; information that the house is at the end of a cul-de-sac could be interpreted by the house-buyer as indicating privacy and quiet, but by the thief as isolation and lack of traffic at night.

Similarly, academic tasks can require varied approaches. For example, in a personal response task, the questions asked by the reader will relate to opinions that are based on personal experiences as well as on prior knowledge acquired from friends, family members, and the media. In a betweentext comparison task, however, there should be no mention of personal experiences; the questions should relate only to the texts in the task description. In experiences with RC-MAPS, personal response and position papers have been found to be the best tasks for introducing situational RC-MAPS because the students need only to look at one text in conjunction with information that they already have.

Next, students need to be made aware of the RC-MAPS Questioning Strategy: what questioning is, why it is used, and when. Questioning written texts is located in cultural domains (Grabe, 2009; Zhang, 2007); many ESL/EFL students come from cultures in which the Western notion of questioning experts is not necessarily promoted. Therefore, questioning rules must first be outlined by the teacher and then modeled on the RC-MAPS to provide direction and scaffolding for the strategy. The RC-MAPS Questioning Strategy consists of the two rules below, based on instructors' experience.

Often ESL students will either give a personal response that does not address specific information or ideas from the text, but only the topic of the text based on their own knowledge; or they will discuss the text with no reference to their own knowledge. Situation-based reading comprehension and academic reading tasks that demand critical thinking require both.

\section{RC-MAPS Questioning Strategy}

RULE 1: The questions must directly relate to the specific content of the text

*RULE 2: The answers must be in 2 parts: one that uses information from the text and another that uses 'outside' information

${ }^{*}$ Outside source(s) are task-dependent; use your knowledge and/or experiences for a personal response task, but use only another text for a cross-text comparison. 


\section{A Situation-Based Comprehension Lesson with RC-MAPS}

In order to provide scaffolding, students initially complete the situation-based RC-MAPS with the teacher as a class, then in small groups and/or pairs, and finally individually. The directions given to students should highlight and reiterate the rules so that they adhere to them in their questions and answers. First, students are asked to display their text-based RC-MAPS. Then they are shown how to create a space for questions for each paragraph on their RCMAPS. This is a simple modification: if students have used an outline style, they should simply make a margin on the left or right (see Appendix C). For charts, they will need to add one more column on the left or right of the existing chart (see Appendix D). With Mind Maps, students need add only a bubble (in another shape or color) to the existing bubbles (see Appendix E).

Second, the RC-MAPS Questioning Strategy should be explicitly presented to and modeled for students. Teachers explain the types of questions and responses that are expected and appropriate for the set task and topic, and they model their own cognitive processes of questioning. Typically, instructors should read the first two sentences aloud and pause, then begin to ask (again, aloud) the questions that are applicable to the task. They should also answer the questions, making sure to refer to both the text and their personal knowledge. Using the first paragraph of the Homeopathy text (Appendix B), for example, instructors might say, "The law of similars gives a small dose to treat symptoms. Do I know of any other medical practice that is similar to that? What about vaccines?" Students write the questions asked on their RCMAPS next to the appropriate propositions (see Appendixes C-E). Typically, teachers should model the first paragraph, and then the second paragraph should be completed by the class with the instructors' guidance. The teacher reads the first sentence or two and then asks the class for a question. The suggestions given by the students are discussed with the class: do they follow the two rules? If so, the students write them on their RC-MAPS. If not, the class suggests how to fix the proposed questions before they are recorded. In small groups or pairs, students are then assigned the task of continuing to create questions for the text. They discuss and create at least two questions per paragraph and monitor that they answer them by referring to the text and their own knowledge. Before the students begin to question on their own, the teacher reiterates the two rules that need to be followed. As students become more familiar and comfortable with questioning, teachers' scaffolding can be gradually reduced so that students can move independently from text-based to situational-based comprehension activities.

Research in strategy instruction indicates that in addition, evaluation of strategy use is important for its successful implementation (Carrell et al., 1998; Grabe, 2009; Yang, 2002). Evaluation is also a skill, so some focus on teaching students how to evaluate their work independently is necessary. RC-MAPS assists in the development of evaluation skills because there is a 
written record that can be reviewed and discussed. Once the questions and answers have been completed, they can be posted for the class to see, or groups can exchange papers. Students are then given instructions to assess the questions and answers: Do they follow the rules? If not, how do they violate the rules, and how can they be fixed? These assessments and suggestions should be shared with the class as a whole, with the teacher providing additional input and explicit feedback.

The final task for students to demonstrate their situation-based comprehension is to include some of their questions and answers in a personal response paper. This is written using the RC-MAPS and submitted for the teacher's assessment and feedback. For the rest of the semester, the instructor should generally require that situational RC-MAPS be handed in with all written assignments based on readings. This gives the students regular practice and over time enhances the fluency and skill (or efficiency and effectiveness) with which they can apply questioning strategies to diverse texts and tasks in the future.

\section{Conclusion}

L2 reading is a complex, interactive, and integrative process (Heeney, 2005; Kintsch, 1998; Koda, 2005; Urquhart \& Weir, 1998). Academic reading often requires more than a text-based understanding because students are asked to apply a text to diverse tasks (Heeney; Shih, 2002; Yang, 2006; Zhang, 2007). Research has demonstrated not only that metacognitive strategy instruction improves reading comprehension (Allen, 2003; Carrell et al., 1998; Fraser, 1989, 1999; Grabe, 2009; Heeney; Macaro \& Erler, 2008; Yang, 2002, 2006; Zhang), but that there is a best practice for teachers to follow, namely, using a direct-strategy teaching approach that explicitly focuses on what the strategy is, why it is important, how it is used, when and where it is applied, and how it is evaluated (Allen; Carrell et al.; Grabe; Heeney; Shih, 1992; Yang, 2002, 2006; Zhang). Although research has given teachers direction regarding the approach to use when providing strategy instruction in their classrooms, it has not provided them with the required teaching tools to achieve this goal. RC-MAPS represents one instructional technique that provides teachers with an easily modified tool to assist them in developing the situation-based comprehension skills of L2 readers in academic environments.

It is important to note that RC-MAPS was developed through teachers' observation of a gap in students' reading comprehension. Currently, RCMAPS has been implemented in only two academic institutions, and the evidence is anecdotal and based only on teachers' and students' observations and comments. Initial responses have, however, been positive. In the classes in which we have used RC-MAPS, we have noted that the quality of written responses to readings has improved for most students. The students who use the RC-MAPS with the Questioning Strategy rules tend to have task-specific 
and appropriate questions that integrate the text with their own knowledge, and they seem to have more confidence in their abilities to complete academic tasks based on readings. These preliminary observations demonstrate a need for further research on specific pedagogical tools that focus on teaching critical questioning strategies in the EAP reading class. Finally, we recognize the need for empirical research on the proposed RC-MAPS technique, and we welcome readers' feedback.

\section{The Authors}

Angela Meyer Sterzik is a doctoral student in applied linguistics at York University in Toronto. She has taught EFL, community ESL, EAP, and TESL. Currently, she teaches EAP at Fanshawe College, and her research interests include academic reading and writing, EAP, and teacher training.

Carol Fraser is an associate professor at York University. She teaches EAP and undergraduate and graduate courses in L2 language learning and teaching, bilingualism, and L2-reading and writing skills. She has published articles on curriculum/test development, reading and writing instruction, the role of language knowledge in SLA, learning vocabulary through reading, and the development of reading fluency in an L2.

\section{References}

Allen, S. (2003). An analytic comparison of three models of reading strategy instruction. IRAL, 41(4), 319-338.

Carrell, P.L., Gajdusek, L., \& Wise, T. (1998). Metacognition and EFL/ESL reading. Instructional Science, 26, 97-112.

Clarke, M.A. (1980). The short circuit hypothesis of ESL reading Or when language competence interferes with reading performance. Modern Language Journal, 64, 203-209.

Day, R.R., \& Park, J. (2005). Developing reading comprehension questions. Reading in a Foreign Language, 17(1), 60-73.

Fraser, C.A. (1989). Reading for independence. TESL Canada Journal, 6(2), 74-86.

Fraser, C.A. (1999). Lexical processing strategy use and vocabulary learning in reading. Studies in Second Language Acquisition, 21, 225-241.

Fraser, C.A. (2004). Reading fluency in a second language. Canadian Modern Language Review, 61, 135-160.

Frazier, L., \& Leeming, S. (2007). Lecture ready 3: Strategies for academic listening, note-taking, and discussion. New York: Oxford University Press.

Grabe, W. (2004). Research on teaching reading. Annual Review of Applied Linguistics, 24, 44-69.

Grabe, W. (2009). Reading in a second language. New York: Cambridge University Press.

Grabe, W., \& Stoller, F. (2002). The nature of reading abilities. In W. Grabe \& F. Stoller (Eds.), Teaching and researching reading (pp. 9-39). London, UK: Pearson.

Heeney, M. (2005). Collaborative awareness reading training (CART): Student and teacher perceptions of the reciprocal teaching approach. Unpublished master's thesis, York University.

Jiang, X., \& Grabe, W. (2007). Graphic organizers in reading instruction: Research findings and issues. Reading in a Foreign Language, 19(1), 34-55.

Kintsch, W. (1986). Learning from text. Cognition and Instruction, 3(2), 87-108.

Kintsch, W. (1998). Comprehension: A paradigm for cognition. New York: Cambridge University Press.

Koda, K. (2005). Insights into second language reading: A cross-linguistic approach. New York: Cambridge University Press.

Macaro, E., \& Erler, L. (2008). Raising the achievement of young-beginner readers of French through strategy instruction. Applied Linguistics, 29(1), 90-119. 
Salataci, R., \& Akyel, A. (2002). Possible effects of strategy instruction on L1 and L2 reading. Reading in a Foreign Language, 14(1), 1-17.

Shih, M. (1992). Beyond comprehension exercises in the ESL academic reading class. TESOL Quarterly, 26, 289-318.

Urquhart, S., \& Weir, C. (1998). Reading in a second language: Process, product, and practice (pp. 37-46). London: Longman.

Vygotsky, L.S. (1978). Mind in society: The development of higher psychological processes. Cambridge, MA: Harvard University Press.

Yang, Y. F. (2002). Reassessing readers' comprehension monitoring. Reading in a Foreign Language, 14(1), 18-42.

Yang, Y.F. (2006). Reading strategies or comprehension monitoring strategies? Reading Psychology, 27(4), 313-343.

Zhang, L.J. (2007). Constructivist pedagogy in strategic reading instruction: Exploring pathways to learner development in the English as a second language (ESL) classroom. Instructional Science, 36(2), 89-116. 


\section{Appendix A: RC-MAPS: Text-Based Comprehension Options}

1. Mind Map Styles (for description and classification texts as per Jiang \& Grabe's, 2007, suggestions).
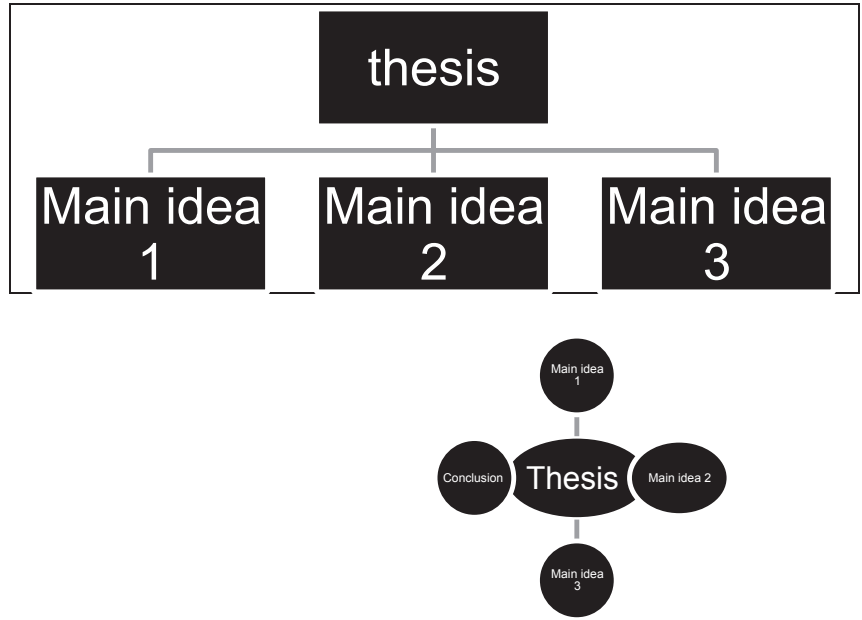

2. Outline Style (For narrative and time-line texts (Jiang \& Grabe).
A.
i.
B.
ii.
iii.

3. Chart Style (for cause-effect, problem-solution, description, classification, and for-against texts, as per Jiang \& Grabe, 2007)

\begin{tabular}{lll} 
Paragraph Main idea Support(s) \\
\hline
\end{tabular}

\begin{tabular}{lll}
\hline $\begin{array}{l}\text { Homeopathy developed in 1700s- } \\
\text { didn't like current medical practices. }\end{array}$ & $\begin{array}{l}\text { Based on } 3 \text { principles: law of similars, } \\
\text { minimum dose, and single remedy. }\end{array}$ \\
\hline
\end{tabular}

2

3

4

5 


\section{Appendix B: Homeopathy}

Homeopathy was developed in the 18th century by the German physician Samuel Hahnemann because he was not happy with the most commonly used medical treatments of the time. His theory of medicine was based on three principles: the law of similars, the minimum dose, and the single remedy. The law of similars came as a result of observation; he noticed that he developed symptoms of malaria after taking a strong dose of the malaria treatment quinine. This led him to believe that if a large amount causes symptoms in a healthy person, then smaller amounts could treat those same symptoms in an ill person.

Homeopathic medicine involves prescribing drugs that duplicate the symptoms of an illness. A homeopathic doctor will prescribe a drug made from plants, herbs, or other natural materials that would cause the same symptoms the patient is suffering in a healthy person. The classic recipe is one grain of the required herb mixed with 99 parts of milk sugar. The solution is diluted further by the homeopathic doctor with milk sugar until he reaches the 30th time.

Many scientists dispute the validity of homeopathic remedies, but clinical trials have provided some empirical evidence that homeopathic patients can show positive results. Practitioners and patients do not care about the physiological mechanisms behind this phenomenon: they simply care that it works for them.

Allopathic (conventional) medicine tends to attempt to create effects that are different from a disease or an illness, and many practitioners of allopathic medicine have rejected homeopathy as sham treatment. However, not all conventional treatments work, so many people accept homeopathy as a valid alternative.

Homeopathy is practiced worldwide, and the number of homeopaths has increased in the US to approximately 3,000 in the late 1990s from fewer than 200 in the 1970s. Homeopathy, like conventional medicine, has empirical support, anecdotal evidence, and can cure ailments; it is a valid course of treatment.

(Adapted from Frazier \& Leeming, 2007) 


\section{Appendix C: Situational RC-MAP Outline Style}

Questions and Answers

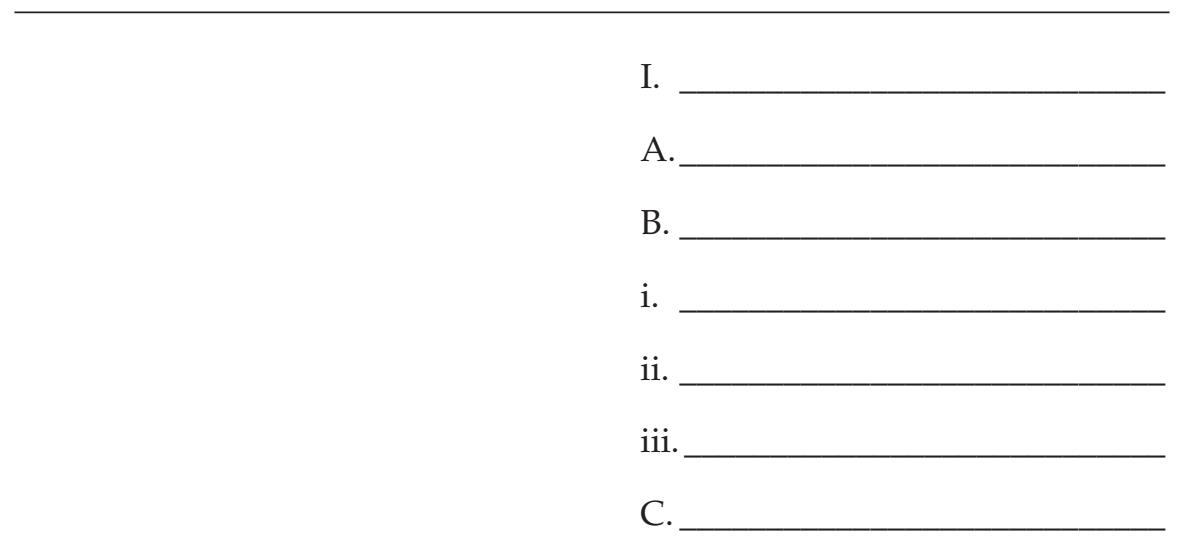




\section{Appendix D: Situational RC-MAP Chart Style}

\begin{tabular}{lll} 
Main ldeas & Support & Questions \\
\hline $\begin{array}{l}\text { Homeopathy developed } \\
\text { in 1700s—didn't like }\end{array}$ & $\begin{array}{l}\text { Based on 3 principles: } \\
\text { current medical practices. }\end{array}$ & $\begin{array}{l}\text { 1. Does one ingredient actually } \\
\text { fight all symptoms - doseme and single remedy }\end{array}$ \\
& & $\begin{array}{l}\text { diseases have many symptoms } \\
\text { (e.g., the common cold) }\end{array}$ \\
& $\begin{array}{l}\text { 2. How has medicine has } \\
\text { changed since the 1700s? }\end{array}$
\end{tabular}

3. Write the answers to all your questions from above.

1.

2.

3.

4.

5.

6.

7.

8. 
Appendix E: Situational RC-MAP Mind Map Style

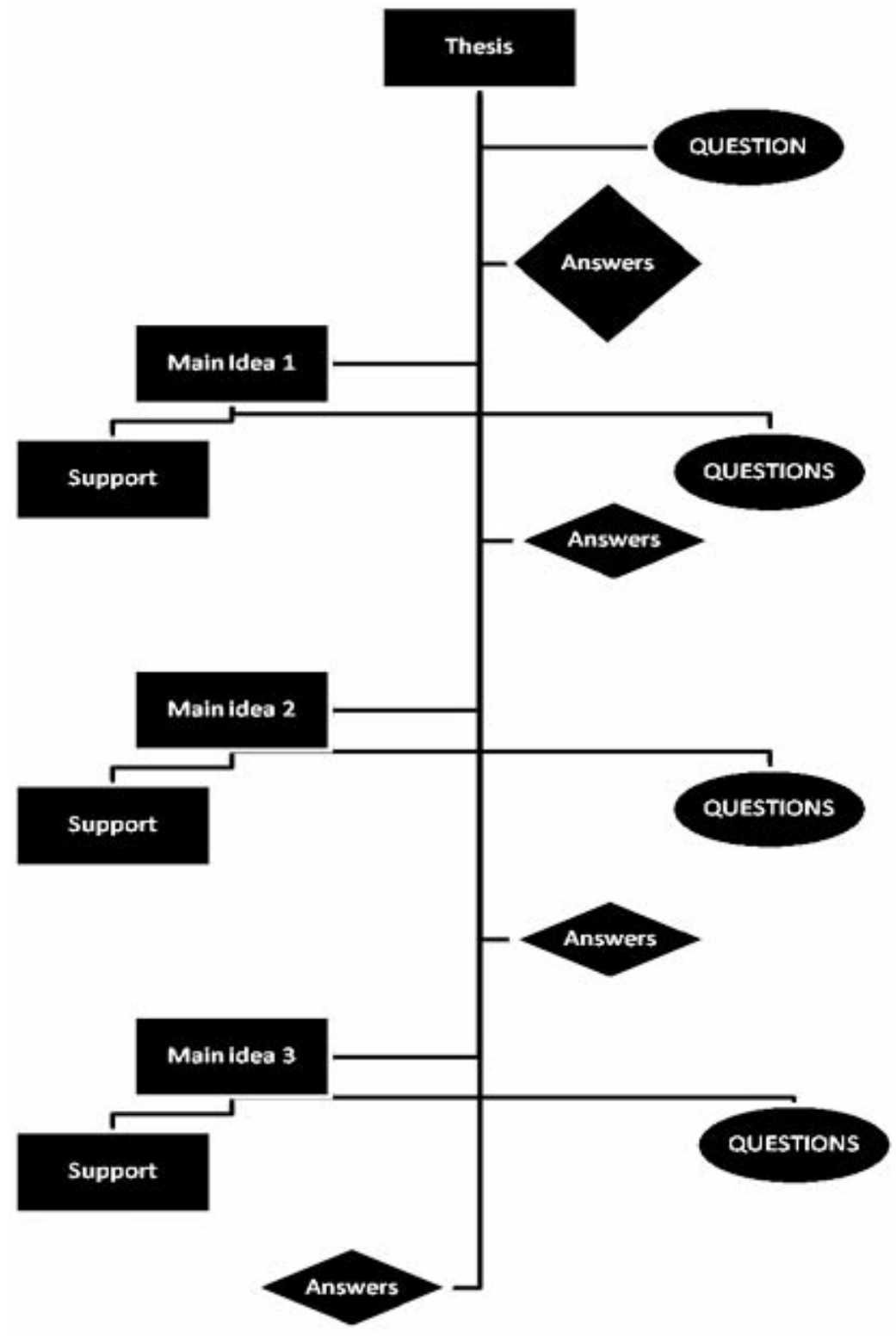

